\title{
TRADICIÓN TÓPICA Y COMPLEJIDAD
}

\section{-TEXTUAL}

1. Una de las características más unánimemente buscada y aceptada en el texto artístico dentro de los últimos decenios es sin duda la de su complejidad. De ella derivan nociones como las de polisemia o polisentido (Barthes) y la de polivalencia (Schmidt), a través de los cuales pretende explicarse Ia csencia de la literariedad en los distintos entendimientos modernos de la misma, lingüístico-poético y pragmático-cultural; si bien es preciso advertir que el designado sumariamente como entendimiento pragmático-cultural (Van Dijk, 1976; M. Corti, 1976; M. L. Pratt, 1977; W. Mignolo, 1978; S. J. Schmidt, 1979) significa más bien unạ "desestimación" de los fundamentos objetivos de la literariedad tradicionalmente entendidos (García Berrio, 1973).

Como es igualmente notorio, la noción de complejidad textual, así como sus correlatos de polisentido y polivalencia, supone la proyección sobre la misma de dos parámetros distintos: de una parte, el del texto mismo como objeto lingüístico-cultural concreto producido por un autor en dialéctica con su propio presente-pasado histórico; de otra parte el del lector, que es no sólo el destinatario teórico contemporáneo del autor, sino también el conjunto de lectores y lecturas futuras del texto. En tal sentido el desarrollo actual de una teoria del lector, o si se quiere de una poética de la lectura, viene a configurar sin duda una imagen completa del texto, que no existía previamente en la analítica tradicional del texto artístico, amputada de ella, o que al menos no la reflejaba sistemáticamente.

A mi juicio, sin embargo, lo que ha sucedido en la poética actual con demasiada frecuencia - de modo fatalmente justificable, por otra parte- es que el deslumbramiento producido por las nuevas luces ha entenebrecido demasiado drásticamente las valoraciones tradicionales. Así, en ocasiones por pre- 
sión polémica, otras por explicable limitación del esfuerzo personal, a veces también, preciso es reconocerlo, por incultura y snobismo, se hace imprescindible recordar que estamos construyendo quizás con indeseable frecuencia una descripción tan limitadamente parcial del complejo cultural denominado texto literario, por lo menos como aquella otra clásica interprẹtación del arte clásico fundada en sus dos polos en la proclamación de una semántica de certezas (Barthes, 1966).

En algunas ocasiones he alertado ya personalmente del peligro de los nuevos bienes (García Berrio, 1977; García Berrio y Vera Luján, 1977: 257), -dicho además esto con el mayor respeto y sin sombra de ironía peyorativa-; y sobre todo quizás, a mi juicio, los positivos riesgos para el estatuto científico y funcional de la operación crítica los encierran las más drásticas afirmaciones del sin duda más atractivo y movilizado postulado de la pluralidad de lecturas. De la misma manera estimo de sentido común, que una interpretación basada demasiado parcialmente en el criterio de relatividad de la lectura no puede desplazar, en último término -ni siquiera para el arte más experimentalmente moderno--, a la descripción objetiva de la realidad texto (Segre, 1970: 24).

Sin embargo no creo ya fecundo para la critica literaria actual el sepultarse, una vez más, en denuncias puramente teóricas y disensiones generales metateóricas. Y sobre todo, con un discurso en tal sentido me parecería que desperdiciaría la ocasión que depara la entidad de las personas e instituciones comprometidas en este coloquio. En el entendimiento global de mis proposiciones anteriores, abordaré aquí, en términos concretos, una sola de las facetas de la complejidad textual: la que deriva de la condición tópica o tradicional-literaria de los textos; aspecto del que me vengo ocupando desde hacc bastantes años y al que he dedicado libros, artículos y ponencias.

Para adelantar ya en concreto el objeto que motivará mis reflexiones, declararé que, por razones fáciles de comprender, me he propuesto la observación de un conjunto textual clásico, que cumpla las condiciones mínimas de representatividad o importancia objetiva histórico-literaria, al tiempo que, por su propia consistencia textual, facilite las operaciones de co- 
tejo intertextual en condiciones adecuadas de homogeneidad. Mis reflexiones sobre la complejidad textual derivada de la. integración tradicional tópica de los textos literarios, se mueven por ahora -y es sobre lo que brevemente me propongo reflexionar en esta ocasión- en el seno de los sonetos amorosos españoles de la tradición petrarquista, durante el siglo XVI y. la primera mitad del XVII; alcanzando la producción de autores como Garcilaso de la Vega, Fernando de Herrera, Lope de Vega, Quevedo y Góngora. No cabe duda, a mi juicio, de que la muestra cumple las condiciones a que me he referido ante: riormente.

1.1. Mi experiencia previa sobre el funcionamiento tópico de la renovación y progresión cultural, se había centrado desde hace unos diez años en el dominio de las ideas teórico-literarias contemporáneas de los sonetos a que ahora voy a referirme. En un conjunto dilatado de libros y artículos (destacaré sólo entre los primeros García Berrio, 1968, 1975 y 1978) he ido examinando el lento fluir de las ideas literarias a lo largo de esa gran "edad renacentista" de la teoría europea entre los años 1500 y 1650 , que comprende por tanto un conjunto de correcciones paulatinas y progresivas del bloque doctrinal tópico de la poética renacentista, para articularse en una poética del Manierismo bien perfilada, y una poética, o mejor quizás, una retórica del Barroco.

La filosofía de la progresión cultural que ha presidido el enfoque de tales investigaciones se identifica, sin más, con la añeja tradición de la tópica cultural de E. R. Curtius (1948) si bien con las lógicas modificaciones y ventajas deparadas por mi objeto de atención, mucho más restringido. A diferencia del gran maestro europeo, yo he atendido a la evolución de un sistema tópico quizás en mayor detalle, en la medida en que no he perseguido la evolución de estilemas genéricos, sino la de un conjunto de axiomas y principios teóricos que llevan a constituir un sistema cerrado, a modo de gramática restringida, que es el conjunto de ideas literarias, retórico-poéticas, que sustentaban la ideología estética renacentista (García Berrio, 1979). El espacio de tiempo tomado en cuenta para estudiar la evolución ha sido además en mi caso mucho más 
corto, y por tanto también más propicio a la condensación sistemática.

Las conclusiones principales, básicamente sustentadas, de la evolución tópica en el sistema de la poética renacentista se reficren en primer lugar al desmontaje de prejuicios sobre la singularidad u ocurrencia feliz de un autor o grupo intelectual orgániço más o menos personalizado. Por el contrario, según mi obscrvación de miles de datos singulares, la ocurrencia feliz que con frecuencia ha cxaltado la historia literaria, vinculada a un autor o persona, no es otra cosa que la cristalización en esc caso de un conjunto de tendencias -o de antitendencias, según las ocasiones- opcrantes desde mucho antes, y a su vez orgánicamente derivada, por deducción positiva o contraste, del conjunto sistemático cuyas leyes regulan y organizan la tópica, en este caso la tópica teórico-literaria.

Si la personalización de la evolución antitópica es, como acabo de decir, fruto de comprensibles y hasta económicas simplificaciones de la realidad, aún sucle ser más drástico e inexacto el establecimiento por la historia literaria de límites cronológicos tajantes entre edades y corrientes de gusto -como Renacimiento/Manierismo/Barroco. Vale aquí también, a mi juicio, más bien la imagen de cristalización a la que antes me refería. Aclarémoslo quizás con un ejemplo concreto: la evolución de la ideología estética del Renacimiento ad Manierismo, no se produce ni en bloque ni de una sola vez. Piénscse que al hablar de la estética del Renacimiento estamos aludiendo a un sistema de lopoi de importante complejidad. $Y$, de la misma manera que la fonología diacrónica ilustrara ya, a mi juicio ejemplarmente, las diferencias de comportamiento entre la evolución de un elemento ácl sistema y la del sistema como conjunto; así tambićn cl Manierismo como sistcma o complcjo estético global es meramente el resultado de un conjunto muy preciso de elementos de cambio que cvolucionan paralelamente a ritmos distintos, pero que para un determinado corte vertical de la cvolución, y en un momento dado, representa ya una imagen inasinilable a la de los sistemas previo y sucesivo.

Concretándonos a nuestro ejemplo, y a nuestra propia experiencia de trabajo, es básicamente la cvolución de una con- 
ciencia artística contenidista-didáctica a otra form for $_{1-}$, snista, definida entre las polaridades de los tres grandes tópicos mayores de la estética renacentista: ingenium/ars, delectare/ docere y verba/res, la que en un determinado momento-cn Italia entre 1550 y 1580 - permite hablar de una estética mayoritariamente cvolucionada $y^{\prime}$ manierista cn tratadistas aristotélicos como Ludovico Castelvetro o comentadores horacianos como Francesco Luisini. Sin embargo, ni siquiera en estos autores mencionados la totalidad de los tópicos del sistema, ni aun la simple relación comprometida on las dualidades mayores, presenta una línea de escisión homogénea y clara.

En el plano de la teoría literaria del período que venimos considerando, el estudio minucioso de cada uno de los documentos concretos de poćtica y retórica, dificulta en gran medida el limpio trazo de las grandes categorías culturalistas creadas por esa gran Historia de mayúsculas, tan importante al menos y necesaria como las mismas verificaciones filológicas quc la someten a prueba, la tensan y ajustan. Conduciendo, por tanto, estas reflexiones previas a nuestro objeto de estudio actual, confesaré mi presupuesto previo al estudio de los textos líricos amorosos, ofrecido por la investigación previa de su ideología estética contemporánea. El texto se constituye como un complejo de entidades tópicas mínimas, en evolución lentísima, en la que los rasgos de innovación genial deben ser siempre mirados con recelo y valorados como tales en su exacta dimensión de componentes de un sistema tópico, lo cual no implica, como veremos más adelante, que se nieguen los valores de literariedad/poeticidad, ni las jerarquías de novedad creativa o acierto de realización.

1.2. La experiencia de la lírica amorosa clásica curopea como conjunto sistemático de textos reelaborados desde un bloque limitado de temas, estructuras expresivas y convenciones pragmáticas tradicionales, apunta en primer lugar al necesario refinamiento de la noción de contexto. Como señalábamos antes, tambićn pucde hablarsc en nuestros días con justicia de un cierto deslumbramiento sufrido por la crítica actual tras la cnriquecedora toma en consideración de la noción social de 
contexto. Durante decenios, si no siglos, los hechos artísticos habían sido "purificados" hasta el exceso en la concepción de críticos e historiadores; la creación literaria se presentaba como un diálogo puro, sin contagios históricos, entre el artista inspirado y los universales abstractos de la poeticidad o la litcrariedad. La imprescindible entrada del parámetro social ha iluminado más satisfactoriamente que nunca importantes móviles y aspectos de ese antojo metafísico de la creación pura intraartística. Gracias sean dadas a la sociocrítica, pues, por haber llenado de exacto cóntenido la noción de contexto.

Pero, como toda novedad engendra exceso -o al menos a ese riesgo se dejan conducir muchos-, conviene no olvidar, junto a los hechos sociales, la importancia fundamental que tiene, dentro del contexto general histórico de una dada obra de arte verbal, el propio componente contextual intraliterario como elemento indescontable y central del contexto social. Esta precaución, que puede resultar en apariencia quizás. obvia y superflua, ha desembocado sin embargo en un conjunto de vacios, de situaciones de hecho de la historiografía literaria, en las que la carencia de una descripción rigurosa y precisa del contexto literario condena todo análisis individual del texto a simplificaciones e ignorancias muy lamentables; al mismo tiempo que imposibilita o irresponsabiliza otras funciones críticas tan imprescindibles como las decisiones de valoración o las sanciones de novedad y originalidad.

En el caso de la lírica clásica, aun para el período que en las distintas literaturas románicas abarcaría desde Petrarca hasta Góngora y Marino, tal ausencia nos parece de demasiado peso. Abundan los estudios individuales y de conjunto sobre el género, no escasean los trabajos de determinación de fuentes e influencias, y son quizás hasta excesivos los ensayos analíticos atomistas. Sin embargo mis trabajos en este terreno parten de la conciencia de carencia de una rigurosa descripción, exhaustiva hasta donde lo aconseje la economía científica, del contexto literario. $\mathrm{Y}$, en mi opinión, después de que la estilística cn su calidad de hermenćutica retórica literaria moderna ha agotado ya toda posible sorpresa en la evidenciación de estilemas formales dentro de los análisis inmanentistas, se hace imprescindible y urgente disponer de 
una adecuada teoría del contexto, antes de seguir hablando. de cada texto lírico concreto en términos rigurosos de novedad y valor.

Obviamente dicha descripción que postulo "rigurosa" del contexto pasa por los refinamientos de la poética lingüística actual de tradición estructuralista, por la ya bien organizada disciplina semiológica, y porr las aportaciones de la lingüística actual, muy en concreto de aquellas de sus áreas más directamente convocadas a la aclaración del texto, como son las gramáticas textuales (Dressler ed., 1978; J. S. Petöfi y García Berrio, 1979). Pero sobre todo, y si he de invocar mi propia experiencia, la más fructífera ayuda la ofrecerá una saludable actitud de confianza en la.capacidad de autoorganización de los propios materiales de la realidad; lo cual tras de tantos decenios de cautela empírica, de especulación metateórica y de extrema parquedad en la verificación real de los modelos, que todos nos hemos impuesto, viene a aportar una vía muy natural de beneficioso enriquecimiento, una. ayuda exterior y una fuente de seguridades objetivas.

2. Regularmente la aparición de un soneto clásico al conocimiento y regulación actual del lector, el crítico o el historiador de la literatura se produce en términos que no dudamos en calificar de simplificación antológica. Sorprende saber, por ejemplo, incluso a personas de gran cultura, que el número de sonetos amorosos de Herrera excede bastante los trescientos, o que los de Lope de Vega son mucho más de mil (O. Jörder, 1936); siendo así que los sonetos verdaderamente recordados de estos autores no exceden en ningún caso del centenar. Sorpresa que aún es mayor si, puesto alguno de los sonetos anodinos de esos grandes creadores al lado de otras composiciones contemporáneas, de consumo meramente so: cial, tales como las de "relaciones" de fiestas y academias, escritos por ingenios menores o incluso meros aficionados locales, las diferencias temáticas y hasta constructivas entre ambos textos no son tan notables que comparezcan en el caso del gran escritor con absoluta nitidez los "rasgos de genio". Por último, aun dentro de un mismo autor, el soneto famoso, genial y antológico -pongamos por ejemplo el tan conocido 
de Quevedo "Cerrar podrá mis ojos la postrera"- se configura casi siempre como un texto de genial acierto, generalmente plasmado en el conjunto de decisiones compositivas microtextuales, entre un grupo de otros textos de valor literario objetivamente mucho más bajo, en los que se evidencian sin embargo identidades temáticas casi absolutas, e incluso paradigmas de construcción macrotextual muy semejantes.

Toda obra literaria, por tanto, todo soneto clásico en el ejemplo que vengo desarrollando, aparece consti:-ida como un impulso más dentro del organismo de incalculable complejidad que es la tradición literaria. El artista clásico a la hora de la creación se fijaba, consciente o inconscien:mente, modelos tradicionales muy inmediatos. $\mathrm{Y}$, por más fuertes que scan las presiones inconscientes del mecanismo concreto social contemporáneo, no cabe duda de que en el momento en que Góngora, por ejemplo, se pone a escribir uno de sus sonetos (Crawford, 1929; Fucilla, 1960) la inmediatez modélica de sus fuentes-Petrarca, el Tasso, etc.- representa un grado de responsabilidades directas en la fisonomía de este texto concreto muy superior al de cualquiera de los incidentes biográfico-sociales del autor en ese mismo día. Lo que, insistiremos, no trata de restar importancia a la responsabilidad última de las incidencias sociales en la personalidad individual y en la creación artística de Góngora, ni de cualquier otro escritor; sino por el contrario viene a destacar la importancia de los hechos de tradición literaria como parte muy importante dc ese complejo hasta ahora no exhaustivamente descrito al que se denomina contexto social de la literatura.

3. En dos aspectos básicos de la organización textual me he fijado hasta el presente a la hora de establecer el marco general tipológico de los sonetos amorosos clásicos, dentro del cual puede explicarse la peculiaridad de cada texto por relación al conjunto. Genéricamente hablaremos para comenzar de la dimensión semántica y la dimensión sintáctica del texto. Pero, inmediatamente se hacen necesarias ruevas precisiones, ya que al considerar la dimensión semántica con independencia de la sintaxis, se incide inmediatamente en importantes vertientes del problema general de límites entre semántica y sintaxis. 
Una nueva realidad a distinguir en la estructura lingüística del texto viene a aclarar sin embargo en la práctica, paradójicamente, muchas decisiones difíciles planteadas a raíz del problema anterior. Haciendo referencia a la diferenciación habitual en lingüística del texto -pero fácilmente conectable, por lo demás, con categorías analógicas o paralelas de la tradición retórica, el estructuralismo europeo y la gramática generativa- entre macrocomponente y nicrocomponente textuales; $y$ al tener que delimitar, en ambos componentes los dominios sintáctico y semántico, se perfila a mi parecer mucho más nítidamente el contenido de la temática como parte correspondiente a la semántica macrocomponencial, en oposición a la semántica microcomponencial, que en la práctica recorre el ámbito tradicionalmente atribuido a la semántica sin más. Análogamente el ámbito de la construcción macrotextual, o en cierto tipo de textos la argumentación textual (A. Naess, 1975; J. S. Petöfi, 1980), presenta quizás con superior claridad a la que se puede dar a propósito del nivel sentencial, la diferencia entre sintaxis y semántica, oponiéndose así temática a construcción, y una y otra a sintaxis $y$ semántica, según el siguiente esquema:

Contenido

Organización

Macrocomponente

Microcomponente

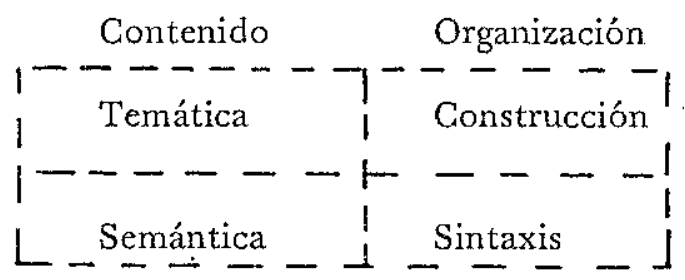

3.1. Soy perfectamente consciente del gran número de problemas lingüísticos actualmente en situación de debate que implican las decisiones prácticas adoptadas en el punto anterior. Explícitamente yo los he discutido ya en trabajos monográficos (García Berrio, 1980; y sobre todo 1979a), cuyo contenido se hace aquí imposible de sintetizar. A mi juicio, sin embargo, las cuestiones más intrincadas lo son a nivel de depuración teórica, lo que no impicle sin embargo, en líneas 
generales, el procesamiento tipológico de los textos previo a la configuración de un cuadro de corrientes tópicas.

Para ejemplificar aquí con una típica cuestión, quizás la más difícil e inestable aun de este conjunto de presupuestos teóricos, aludiré simplemente a un problema relativo al nivel temático: el proceso de detcrminación del tema en el texto. Cuestión ésta que ha sido casi exclusivamente hasta ahora abordada en niveles sentenciales (O. Dähll, 1973; Sgall y otros, 1973), y sólo en algún libro reciente planteada en su dimensión textual (L. K. Jones, 1977), si bien de modo aún meramente preliminar. Este problema, sin embargo, queda notablemente simplificado en el tipo de textos, los sonetos, sobre los que he trabajado hasta el presente. El soneto es un modelo textual generalmente argumentativo y unitemático por definición. Ya Dante, en la polémica sobre la lírica, definía la peculiaridad unitemática de esta composición al señalar el concetto, es decir el tema del soneto, su contenido semántico básico, como fábula de la composición, o sea como equivalente del argumento de acción en tragedias o novelas. Por lo común, además, la expresión del tema central del soneto viene confiada por una suerte de regla métrica de la composición al terceto final, en una especie de síntesis o reinsistencia explícita del tema desarrollado en el resto, bien manifiestamente, bien indirectamente a través de "suspensiones" o "ponderación conceptuosa" en la terminología de la época.

El proceso de la determinación del tema en el texto, o más bien el de la jerarquización de temas en la estructura semántica del soneto, si bien se presenta como un problema teórico aún no explícítamente resuelto, asumido por mis tipologías temáticas, no las invalida a mi juicio en absoluto. En último término la selección del tópico textual que supone nuestro trabajo se basa en decisiones intuitivas muy generalizadas $y$ raramente erróneas; tal como se viene practicando secularmente en multitud de operaciones, literarias o no, como las de poner el título adecuado a un libro, el titular a un parte informativo, la síntesis feliz en una conversación, etc. En varias ocasiones he tenido que argumentar contra la inaceptable proposición de que la poética ha de anular su actividad y es- 
perar a realizar sus operaciones, incluso las de límites más estrictamente próximos a la lingüística, a que ésta haya resuelto satisfactoriamente todos sus problemas teóricos. En este caso la "paciencia" de la poética, como una más de las disciplinas de aplicación de la teoría general lingüística, podría condenarla a un amortiguamiento innecesario.

Contrariamente, y confío en que mis trabajos puedan aclararlo modestamente en alguna medida, lo que he denominado antes capacidad de organización intrínseca de la realidad misma, creo que puede brindar soluciones brillantes e inesperadas al debate teórico sobre la formulación lingüística en la determinación del tema. Téngase en cuenta que una tipología temática como la que yo propongo, se realiza básicamente como trabajo de integración de clases temáticas, correspondiendo a operaciones previas de cotejo entre textos a los que intuitivamente se les ha atribuido identidad temática. De tales operaciones de contraste salen sin duda reforzadas las identidades temáticas centrales, y limadas las adherencias temáticas marginales de discrepancia intertextual. El paso de ese nivel de observación al inmediato de formulación de los resultados de solidaridad como sistemas de reglas, se me ha ofrecido relativamente facilitado desde la experiencia deductiva que he operado. (García Berrio, 1979b); por lo menos con resultados incomparablemente más fructíferos y menos costosos de los que, personalmente, ha podido llegar en otros casos a través de procesos teóricos de inducción.

3.2. Por consideraciones obvias relativas a la propia índole del tema, y sobre todo a las circunstancias concretas de su exposición, no puedo proceder aquí a una descripción, siquiera sea sumaria, del contenido de 'mi tipología temática. Su resultado esquemático se encuentra en un gráfico * que corresponde a la primera formulación de la misma (García Berrio, $1978 \mathrm{a}$, publicado después en J. S. Petöfi, A. García Berrio, $1979 ; 311-366)$. Básicamente dicho esquema ilustra el procedimiento general de toda organización tipológica, en la que el nivel de entrada, 1, representa la fórmula general cumplida Berrio. 
por la totalidad de los textos de muestra, en este caso la fór. mula de la lírica amoroso-cortés.

Tras sucesivas aplicaciones de condiciones en los niveles inferiores -de predicación en el 2, actancial en 3, de modalidades 4 , temático 5 - se va procediendo a la organización de grupos homogéneos de textos con identidad de contenido temático, hasta llegar a las terminales del gráfico; a partir de lo cual no me ha parecido rentable ni informativo proceder a subclasificaciones posteriores de las clases temáticas, que tendrían que alcanzar incluso, en último término, el nivel de la microestructura. Tarea esta, sin embargo, que, cntre otras varias, he realizado parcialmente para una de las terminales, la del carpe diem (García Berrio, 1978b).

Lo realmente relevante entre las enseñanzas de que provee la tipología temática a nuestras consideraciones actuales sobre tradición tópica y complejidad textual, se deriva del hecho innegable de la sorprendente limitación de los tópicos temáticos comprometidos en un sistema textual de apariencias tan complejas como el de la lírica amorosa. En efecto, la combinatoria temático-sintáctica que configura cada texto, sin mencionar además las diferencias microtextuales de formalización lexemática, microsintáctica, etc., contribuye a presentárnoslo -en especial si estamos privados de un adecuado nivel de información tipológico-tópico- como una pieza singular y única. En la estructura del texto de cada soneto resultan sin duda más evidentes los rasgos de singularización que las estructuras básicas comunes. Lo que no quiere decir, sin embargo, que en el proceso de construcción textual no resultan altamente operantes y definitivamente decisivas tales estructuras comunes.

Sin embargo la sistematización tipológica de la temática de los sonetos amorosos clásicos, para una muestra bastante representativa -inicialmente de quinientos sonetos, extendida en la actualidad sin modificaciones importantes a casi el doble-, nos los presentaba organizados en torno a unas ochenta terminales, correspondientes en verdad a poco más de cincuenta tópicos temáticos centrales. Por lo demás, y lo que aún resulta más sorprendente, en el inventario de rasgos temáticos marginales, deducidos de la definición de todos y 


\begin{tabular}{|c|c|c|c|c|c|c|c|}
\hline \multirow{2}{*}{ REPRESENTACIÓN } & \multirow{2}{*}{ SÍNTOMA } & \multicolumn{3}{|c|}{ APELACIÓN } & & & \\
\hline & & POETA MISMO & CONFIDENTE & $\begin{array}{c}\text { DAMA } \\
\text { (OBJETO PRINCIPAL) }\end{array}$ & & & \\
\hline 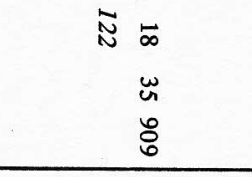 & $\begin{array}{l}\tilde{\sim} \\
\tilde{a} \\
\tilde{\leftarrow}\end{array}$ & & & & 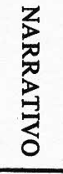 & 孞 & \\
\hline 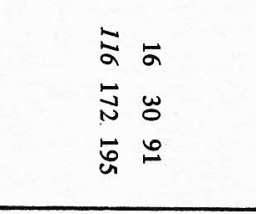 & $\begin{array}{l}8 \\
2\end{array}$ & & & & 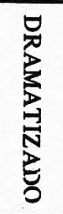 & 窇 & $\underset{\underset{\pi}{x}}{Z}$ \\
\hline 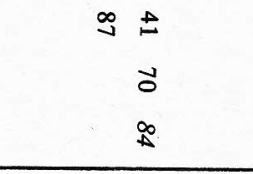 & $\begin{array}{l}\text { i } \\
\text { is }\end{array}$ & & & & 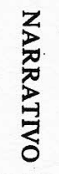 & $g$ & בֶ. \\
\hline 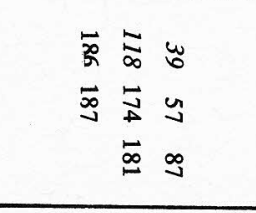 & $\begin{aligned} \vec{t} & b \\
\vec{\omega} & 2 \\
\omega & \infty\end{aligned}$ & & & & 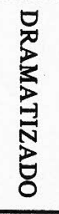 & $\vec{F}$ & \\
\hline
\end{tabular}


cada uno de los sonetos, no aparecen temas nuevos. Es decir, aquellos mismos poco más de cincuenta tópicos determinantes de terminales temáticas centrales se distribuirían también para otros textos como rasgos temáticos secundarios. Y aún he de añadir que, en mi actual revisión en curso de la tipología temática (García Berrio, 1980), determinadas correcciones en la organización y esquematización de la tipología me permitirán, sin forzar en absoluto la estructura real objetiva de la muestra, limitar a poco más de treinta tópicos el inventario general de temas implicados en los sonetos amorosos de la totalidad de los grandes escritores españoles del Siglo do Oro.

3.3. Desde la perspectiva anterior, cada texto se nos presenta como una compleja red de elementos y tensiones que, al mismo tiempo, es no sólo compatible sino hasta lógica consecuencia de la relativa simplicidad del inventario de componentes básicos comprometidos por el sistema.

La investigación del limitado repertorio temático evidencia que no es precisa la existencia de mayor número de componentes temáticos fundamentales para que el "corpus" general de textos construido desde dicho inventario temático, con sus variantes circunstanciales mínimas, garantice el funcionamiento holgado del sistema literario. Pues si el artista se encuentra confortado, a través sin duda de los prejuicios pragmático-culturales de la literariedad, dentro de un universo relativamente restringido, y familiar por tanto, de argumentos temáticos; por otra parte resulta evidente, incluso desde la propia experiencia del lector, que tal restricción temática no llega a ser en modo alguno angustiosa, ni empobrecida.

Diría, por el contrario, que la conjunción de tales mínimo y máximo - restricción temática frente a variedad textualen el sistema de la lírica clásica, resulta congruente dentro de una cierta ecuación de economía comunicativa del sistema literario. Como en tantos otros casos de estructuras. inmanentes de sistemas semióticos evidenciadas por el análisis (Propp, 1928), este principio que he denominado de la economía comunicativa, refuerza precisamente la complejidad de los productos del sistema, que lo son precisamente en vir- 
tud de la combinatoria compleja del inventario básico limitado.

4.1. Evidentemente la antes aludida combinatoria temática implica no sólo la asociación de temas secundarios al tema central, sino sobre todo las fórmulas de construcción textual; es decir, la estructura macrosintáctica de la argumentación textual a través de la cual se organiza hasta cl límite de la microestructura la temática del texto. En mi investigación, el análisis de la tipología macrosintáctica de los sonetos amorosos me ha ocupado con posterioridad al estudio de la temática (García Berrio, 1980a). Como en el caso de la tipología temática, no hay posibilidad en esta ponencia de sintetizar en toda su extensión y notables consecuencias el contenido de aquel trabajo, me limitaré aquí a bosquejar las líneas generales y principios básicos dę la tipología macrosintáctica.

4.2. El principio fundamental organizativo de la tipología macrosintáctica de que he partido lo constituye el hecho de que el soncto es un tipo especial de texto en el que se sobreponen dos organizaciones distintas y simultáneas de cláusulas y cesuras: las métricas y las sintácticas. Cuando las unidades de construcción textual y las marcas delimitativas de la macroestructura sintáctica del texto-soneto coinciden con las cesuras estróficas del soneto (principal entre cuarteto/terceto, secundarias, entre los dos cuartetos y los dos tercetos) se establece el tipo de construcción que he llamado isodistribución textual métrico-sintáctica. En el caso de que la cesura principal no sea respetada, y la continuidad sintáctico-semántica de la expresión textual sobrepase el límite de los tercetos, he considerado que se trata de estructuras en antidistribución. A su vez, la isodistribución puede ser dual o múltiple, según que las cláusulas sintáctico-textuales se organicen, respectivamente, en dos unidades solamente en torno a la cesura principal, o en cuatro cláụsulas autónomas coincidiendo con las cuatro cláusulas metricoestróficas del soneto $y$ sus cesuras.

En la isodistribución cual jucga un papel decisivo la índole explícita/no explícita de las marcas delimitativas y conecti- 
vas. Y en el caso de las explícitas, la condición de enfáticas (imperativo, exclamación, vocativo, intcrrogación retórica, etc.), o no enfáticas (discursivas con conectores). Algunas otras subagrupaciones y modalidades secundarias han sido operadas en mi trabajo de referencia, y pueden ser consultadas por el lector formando parte de la gráfica 2 y 3 de este artículo. Pero su comprensión me parece obvia, y el rendimiento de su aclaración en un artículo de la índole del actual muy escaso. La combinación de los dos principios organizativos hasta ahora referidos nos ofrece ya la posibilidad de elaborar un diagrama arbóreo básico de la construcción textual del soneto (fig. 1), de configuración similar al temático. Constituye también el parámetro básico (vertical en el gráfico 2) de clasificación textual macrosintáctica.

4.3. El segundo parámetro organizativo del reticulado de clasificación macrosintáctica (horizontal en el gráfico 2) lo determina la incidencia actancial en la modalidad funcional del texto. Siguiendo las categorías del famoso esquema sobre las funciones del lenguaje de Bühler, he distinguido en los textos el predominio de una de las tres funciones: apelación -con distintas variedades de actores, que desarrollan la función del actante objeto explícitamente enfocado en la expresión textual-, síntoma y representación. Los textos sintomáticos, centrados en el énfasis expresivo de los propios sentimientos e ideas del poeta emisor-personaje sujeto, establecen la base genuinamente lírica de la tipología. Por el contrario, los textos en representación, que tematizan por esencia realidades y acciones ajenas al emisor-poeta, constituyen por definición el contingente no lírico de la muestra.

En el esquema de la figura 1 no he dado entrada a los componentes de este parámetro por razones de claridad y evidencia obvia. Resulta claro que en todas las terminales del gráfico deben ser introducidas sus categorías como subramificaciones progresivas. Veáse la forma de proceder, por ejemplo, en la rama de la isodistribución dual sin marcas explícitas.

4.4. En conclusión, resulta evidente que si limitado es el número de contenidos temático-tópicos con que juega el siste- 
ma de la lírica clásica, todavía lo es más el de las estructuras de construcción que se ofrecen en el soneto. Sépase, por lo demás, que nuestra investigación ya realizada en el dominio

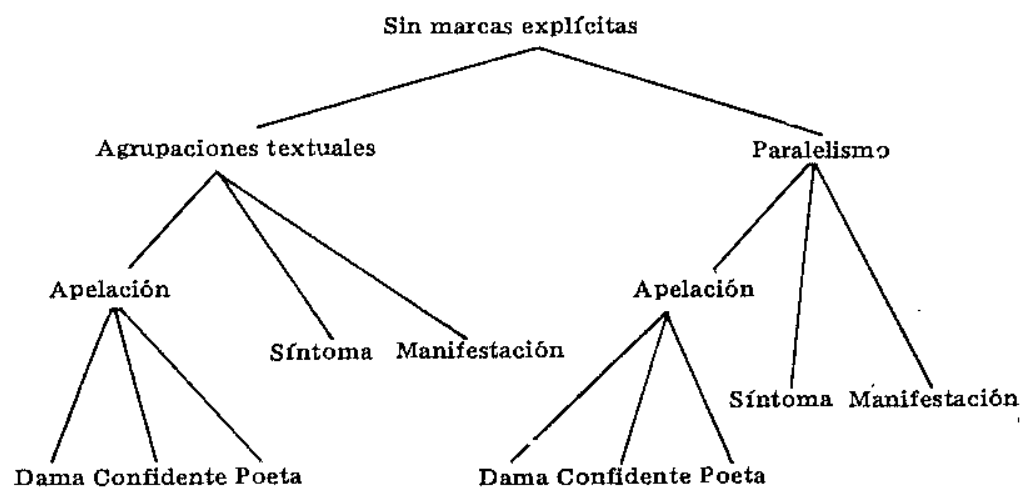

sintáctico se extiende a una muestra más numerosa - mil textos- y más compleja -sonetos amorosos, morales, burlescos, conmemorativos, etc.- que la que determinó el establecimiento de la tipología temática a que he hecho referencia en estc trabajo. Con ambos conjuntos muy limitados de variables operaba el sistema clásico de la lírica; pudiendo ofrecer desde su combinatoria, sin embargo, una variedad de resultados textuales estética y culturalmente satisfactorios, al moverse dentro de una economía de comunicación plenamente lograda.

5. Claro está que a la complejidad de los textos del sistema de la lírica amorosa clásica hemos de añadir aún la acción de un componente diversificador muy rico, responsable en último término de las más plausibles apariencias de individualidad. El conjunto que forman las dos tipologías, semántica y sintáctica, hasta aquí presentadas, explica y permite medir cl parámetro de complejidad del macrocomponente textual. La acción diferenciadora del microcomponente empieza aquí y es, más que importante, decisiva.

Obviamente a niveles de microcomponente existe también una tópica de los estilemas, quizás desde los tiempos de la es- 
tilística y el comentario tradicional de textos, la mejor conocida; pero sin duda no igualmente sistematizada en términos estrictos, contando ya con las importantes modernizaciones que suponen los avances aportados por Dubois, Klinkenberg, y otros (1970; y 1977). Sin embargo, según pienso, hasta el. presente, el dominio del microcomponente representa la zona de la individualización del texto, y por tanto aquel en que el interés y posibilidad de la tipologización se ofrecen más dudosos.

Precisamente, y aunque en ello soy consciente de la necesidad de introducir importantes matizaciones, no deja de resultar a mi juicio válido, en líneas generales, que la eficacia poética del texto viene confiada casi cxclusivamente a la relación microcomponencial del mismo; precisamente porque en ella el autor clásico podía establecer las imprescindibles corrcccioncs a los condicionamientos tópicos del sistema cultural-literario, que resultan evidenciables y mensurables en términos de topicidad del macrocomponente. En tal sentido, el conjunto de convenciones culturales que reclama la propuesta pragmática sobre la literariedad desarrollada en estos últimos años - de la que me hacía eco al comienzo de este trabajose haría patente, en mi esquema, a través de la restricción económica de la combinatoria sintáctico-semántica macrocomponencial, y sobre todo en la extremada limitación de estructuras temáticas y constructivas del sistema.

La literariedad, pues, como punto de partida pragmático o valor cultural quedaba garantizada dentro del universo del arte clásico ai nivel macrocomponencial de mera opción inicial; es decir, cualquier persona culta conocía por reflexión o intuición el "tipo literario" temático-argumentativo a que se ceñía un soneto de carpe diem, y con ello se sabía dentro de un modelo de actividad convencionalizado como literatura. Pero a partir de ahí, y prácticamente ese "a partir de" implicaba la entrada en el universo de decisiones estilísticas incomparablemente más rico y libre que afectan al microcomponente textual, el valor estético, por definición no convencionalizable, quedaba confinado en el dominio del microcomponente textual; aquel precisamente que no obligaba al creador con. 

estructuras tópicas, sino con normas de realización no pac-
tada.

Quedaba así definida, en conclusión, la complejidad del texto clásico, al menos por lo que a la lírica se refiere, como una combinatoria de los factores que integraban la tradición tópica; pero operando dicha tradición en dos bloques de comportamiento claramente deslindados, según lo imponía la naturaleza lingüística misma del texto: el sistema de instrucciones tópicas de literariedad más restringido y responsable de la complejidad controlada del macrocomponente textual, y el conjunto de normas de poeticidad proyectado sobre el microcomponente, interpretable según fórmulas de eficacia y valor individuales muy libres, las cuales permiten concretar precisamente la eficacia estética, o el valor artístico de un texto en términos de una rigurosa dialéctica entre descubrimiento y reconocimiento, gobernada por la tradición tópica.

Universidad de Murcia

ANTONIO GARCÍA BERRIO 

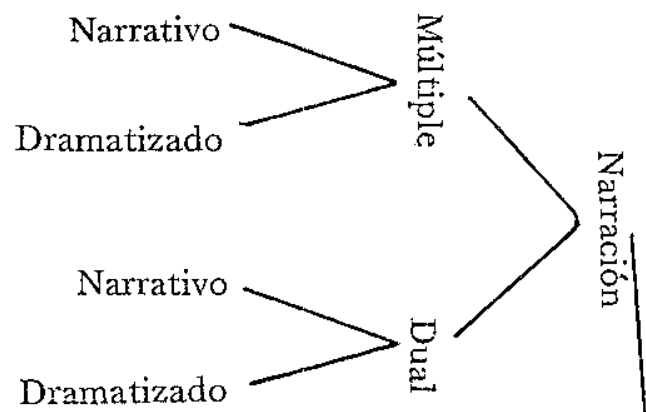

Dramatizado
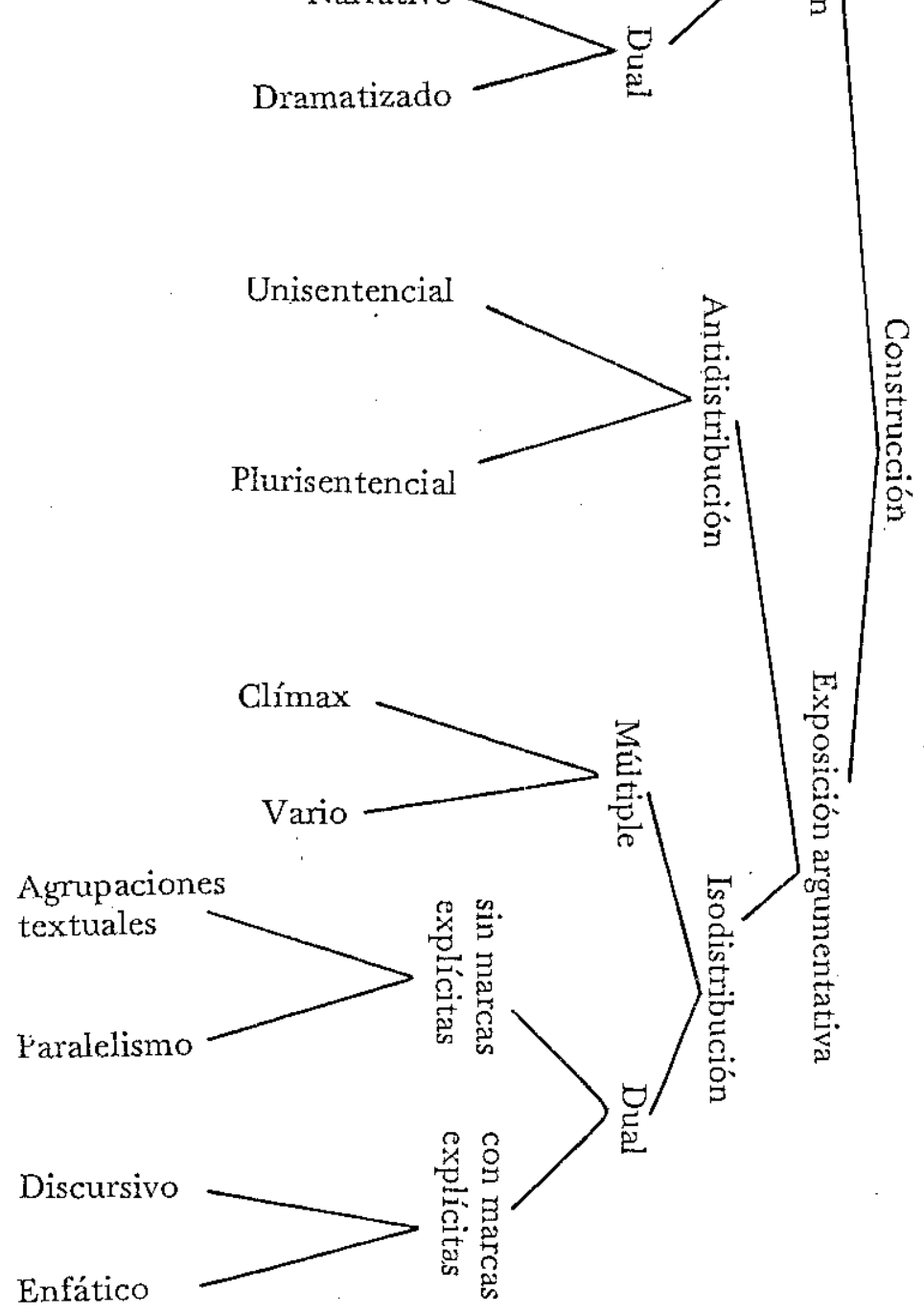


\section{REFERENGIAS}

1966 BARTHES, ROLAND, Critique et vérité, París, Seuil.

1976 CORTI, MARIA, Principi della communicazione letteraria, Milán, Bompiani

1929 CRAWFORD, J. P. W., "Italian sources of Gongora's poetry", en Romanic Review, XX, pp. 122-130.

1948 CURTIUS, E. R., Literatura europea y edad media latina, México, Fondo de Cultura Económica, 1955.

1973 DAHL, OSTEN, Topic and comment. Contextual boundness and focus, Hamburgo, Buske.

1978 DRESSLER, WOLFGANG U. (ed.). Trends in Textlinguistics, Berlin, De Gruyter.

1970 DUBOIS, J. F. EDELINE, J. M. KLINKENBERG, y otros, Rhétorique générale, París, Larousse.

1977 Rhétorique de la poésie, Bruselas, Complexe.

1976 DIJK, TEUN A. (ed.). Pragmatics of Langzage and Literature, Amsterdam, North-Holland.

1960 FUCILLA, JOSEPH G. Estudios sobre el petrarguismo en España, Madrid, Gredos.

1968 GARCIA BERRIO, ANTONIO.España e Italia ante el Conceptismo, Madrid, C. S. I. C. (Anejo LXXXVII de la Revista de Filología Española.)

1973 Significado actual del formalismo ruso, Barcelona, Planeta.

1975 Introducción a la Poética clasicista: Cascales, Barcelona, Planeta.

1977 "Crítica formal y función crítica", en Lexis 1, 2, 189-209. 1978 Formación de la teoría literaria moderna, Madrid, CUPSA.

1978a "Lingüística del texto y texto lírico", en Revista española de lingüistica, 8, 1, pp. 19-75.

$1978 \mathrm{~b}$ "Tipología textual de los sonetos clásicos españoles sobre el carpe diem", en Dispositio, $\mathrm{Hi}, 9$, pp. 243-293.

1979 "Poética e ideología del discurso clásicos", cn Revista de Literatura, XLI, 81, pp. 5-40.

1979a Problemas lingüisticos en una tipología textual, (Seminario en el Instituto de Lingüística Románica de la Universidad de Munich, mecanog.)

19.80 "Realización poćtica microtextual de macroestructuras literarias" (aparecerá en Revista de Literatura).

1980a "Construcción verbal en los sonetos de Lope de Vega," (aparecerá en la Revista de Filología Española).

1977 GARCÍA BERRIO, A. y VERA LUJÁN, A., Fundamentos de teoria lingiïística, Madrid, Comunicación.

1939 JORDER, OTTO, Die Formen des Sonettes bei Lope de Vega, Halle, Max Niemeyer.

1977 JONES, LINDA K., Theme in english expository discourse, Lake Bluff (Illinois), Júpiter Press. 
TRADICIÓN TÓPICA Y COMPLEJIDAD TEXTUAL

103

1978 Mignolo, WALTER, Elementos para una teoría del texto literario, Barcelona, Grijalbo.

1979 PETOFI, JANOS S., "Connexity, coherence, theory, of text", en Coherence in natural languages. Hamburgo, Buske (en preparación).

1979 PETÖFI, JANOS S., García Berrio, A. Lingüistica del texto y crítica literaria, Madrid, Comunicación.

1977 PRATT, MARY LOUISE, Toward a speech act theory of literary discourse, Bloomington, Indiana Univ. Press.

1928 PROPP, VLADIMIR, Morfología del cuento, Madrid, Fundamentos, 1971.

1975 NAESS, ARNE, Kommunikation and Argumentation; Kronberg Ts., Scrip tor.

1979 SCHMIDT, SIEGFRIED J., "Empirische Theorie der Literatur" (mecanog.).

1970 SEGRE, CESARE, Crítica bajo control, Barcelona, Planeta.

1973 SGALL, PETR, HAJICOVA, EVA, y BENESOVA, EVA,

Topic, Focus and generative Semantics, Kronberg, Scriptor. 